On Crystals in the Cavilies of Topaz, which are dissolved by heat, and re-crystalized on Cooling. By Sir David Brewster.

Sir David gave a brief notice of the discovery which he had made, about twenty years ago, of two new fluids in the crystalized cavities of topaz, and other minerals. One of these fluids is very volatile, and so expansible, that it expands twenty times as much as water with the same increase of temperature. When the vacuities in the cavity which it occupies are large, it passes into vapor, and in these different states he had succeeded in determining its refractive power, by measuring the angles at five fuet. Total reflection takes place at the common surface of the fluid of the topaz. 'The other tluid is of a denser kind, and occupies the angles and narrow necks of cavities. The cavities, however, in which the soluble crystals were contained, are of a different kind. They (viz. the cavities,) were imperfectly crystalized, and thus they exist in specimens of topaz which contain the eavities with the two new fluids; they contain none of the volatile and expansible fluid, which is doubtless a condensed gas. 'The crystals which occupy them are flat, and finely crystalized rhomboids. When heat is applied, they become rounded at their angles and edges, and soon disappear. After the topaz has cooled, they again appear, at first like a speck, and then recrystalize gradually, sometimes in their original place, but often in other parts of the cavity, their place being determined by the mode in which the cooling is applied. We understand that Prof. Liebig, who regards these fluids and crystals as peculiarly interesting, has made arrangements to investigate their nature, when taken out of their cavities by Sir David Brewster,-an operation of extreme difficulty, owing to the small size of the cavities which contain them, and the rapid disappearance of the volatile fluid, which rises into a drop, and contracts into a flat disis, as if it were endued with vitality, finally vanishing and leaving a sediment behind it, which, when breathed upon, again becomes fluid.-Pro. Brit. Ass.

Lund. Atbenæum.

\title{
Heath's Cast-Steel.
}

Before the introduction of Mr. Heath's process, which consists in adding carburet of manganese to the melting pot, all steel which was to be worked into a fine edge was made of iron procured from one mine only, that of Dannemora, in Sweden. It was consigned to a house at Hull, at a cost of $38 \mathrm{l}$. per ton, in quantities not exceeding 1100 tons per annum. and marked $L$ in a hoop. 'The price limited its use; but by meaus of this patent the inferior sorts of iron, as those at $15 l$. per ton, may be made available. Steel is made by it which has all the beauty of cast-steel, and all the welding advantages of shear steel. In the manufacture of table knives its advantages have been manifest. Formerly these articles were made by tilting, or rolling, square bars of steel into the necessary shape, thus making blade, shoulder, and tang in one piece; so difficult was this process, that two wasters in a dozen knives were always thrown aside, and workmen's wages were double. Now, the steel blade, made by this process is welded with the iron tang.

Lond. Min. Journ. 